\title{
FILOSOFI HUMOR DAKWAH
}

\author{
Fahriansyah \\ Bimbingan dan Penyuluhan Islam, Universitas Islam Negeri Antasari Banjarmasin, \\ Indonesia \\ Email:fahrisyah611@yahoo.com
}

\begin{abstract}
The phenomenon of the use of Humor in Da'wah Bil Lisan is a sign that the attraction of da'wah objects to the exposure of oral offerings in da'wah is influenced by the presence of humorous insertions in each Dakwah Bil Lisan (Da'wah Oral) , but in reality the use of humor in Da'wah Bil Lisan has a very high level of complexity due to the ability of lecturers in producing very limited humorous offerings which are limited by the existence of values that must be brought as a manifestation of the purpose of Da'wah Islamiyah. Therefore, a philosophical understanding of humor is needed because of the harmony between the purpose of da'wah and the purpose of humor presented in lectures (Da'wah Bil Lisan).
\end{abstract}

KEYWORDS Philosophy, Humor, Oral Da'wah, Da'wah Objects and Da'wah Purpose.

\section{ABSTRAK}

Fenomena penggunaan Humor dalam Dakwah Bil Lisan merupakan tanda bahwa daya tarik objek dakwah terhadap pemaparan persembahan lisan dalam dakwah dipengaruhi oleh adanya insersi humor di setiap Dakwah Bil Lisan (Dakwah Lisan), tetapi dalam kenyataannya penggunaan humor dalam Dakwah Bil Lisan memiliki tingkat kompleksitas yang sangat tinggi karena kemampuan dosen dalam menghasilkan sangat terbatas. persembahan lucu yang dibatasi oleh adanya nilai-nilai yang harus dibawa sebagai manifestasi dari tujuan dakwah Islamiyah. Oleh karena itu, pemahaman filosofis tentang humor diperlukan karena keselarasan antara tujuan dakwah dan tujuan humor yang disajikan dalam kuliah (Dakwah Bil Lisan).

KATA KUNCI: Filsafat, Humor, Dakwah Lisan, Obyek Dakwah dan Tujuan Dakwah.

\section{Pendahuluan}

Penggunaan Humor dalam kegiatan Dakwah Islamiyah bersifat lisan mendapatkan respon positif dari obyek dakwah, hal ini terbukti dengan semakin banyak dan diminatinya penceramah-penceramah yang memiliki rasa humor dalam setiap aktivitas ceramahnya, di Indonesia penggunaan Humor dalam aktivitas Dakwah Islamiyah dipergunakan dalam upaya menarik respon dari pihak-pihak yang didakwahi, seperti Abdurrahman Wahid atau yang akrab dipanggil Gus Dur dalam menyampaikan pandangan-pandangan keagamaan serta kritik terhadap kebijakan pemerintah selalu mempergunakan humor-humor sehingga terbitlah buku kumpulan kolom Abdurahman Wahid di majalah Tempo 
dengan judul : "Melawan Melalui Lelucon", bahkan KH. Zainuddin MZ diberi julukan Da'i sejuta umat dikarenakan memiliki kemampuan memasukan humorhumor dalam setiap ceramahnya.

Pada masa sekarang dimana kemajuan dunia informasi berupa kemajuan dalam dunia internet muncullah beberapa Penceramah yang mampu menarik generasi muda dengan memasukan humor-humor dalam ceramah agamanya, misalnya : Ustad Abdul Somad (UAS), Ustadz Adi Hidayat, dan yang paling akhir muncul pada tahun 2018 yaitu Ustad Hasan Haikal, dan kitapun menyaksikan bahwa perhatian orang untuk mendengarkan ceramah-ceramah agama semakin bergairah.

Namun ditengah-tengah penggunaan Humor para Pendakwah yang semakin gencar dilaksanakan justeru ada keperihatinan tentang penggunaan Humor dalam ceramah-ceramah da'i yang suka berhumor dalam ceramahnya, seperti yang disampaikan oleh Salim Ibnu Abdul Choliq:

Geerr...?! Hahahaha....hihihi...

Sontak tawa jamaah pengajian meledak tatkala melihat tingkah aneh sang da'i. Tingkah "lebay" si da'i dan gaya bicaranya yang dibuat-buat ternyata membuat sebagian besar jamaah terpingkal-pingkal dalam tawa. Entah jamaah pengajian paham atau tidak materi pengajian, yang penting lucu.

Di sisi yang lain, acara suatu pengajian berubah menjadi arena tawa ria karena sang da'i lebih suka ngebanyol ketimbang menyampaikan materi-materi terbaik. Dan biasanya, da'i yang kondang dengan dagelannya lebih banyak "diminati" daripada dai-dai yang konsisten menyampaikan ilmu syar'i. Sebagian dai bahkan sampai kebanjiran "order" mengisi ceramah karena popularitasnya sebagian dai ndagel. Apa harus begini kalau berdakwah?

Tulisan ini mencoba memaparkan sisi filosofis penggunaan humor dalam dakwah dalam bentuk ceramah agama (dakwah bil lisan) agar humor yang dipergunakan tidak terlepas dari tujuan esensial dari aktivitas Dakwah Islamiyah.

\section{Kajian Pustaka}

\section{Definisi Humor}

Dalam Kamus Besar Bahasa Indonesia humor adalah : (1) sesuatu yang lucu: ia mempunyai rasa --; (2) keadaan (dalam cerita dan sebagainya) yang menggelikan hati; kejenakaan; kelucuan, Dari Wikipedia bahasa Indonesia dinyataka Humor (bahasa Inggris: humour, atau humor) adalah sikap yang cenderung dilakukan untuk membangkitkan rasa gembira dan memicu gelak tawa. Istilah ini berasal dari istilah medis Latin kuno, yang mengajari bahwa keseimbangan cairan dalam tubuh manusia, yang dikenal sebagai humor (bahasa Latin: humor, "cairan tubuh"), yang diatur oleh kesehatan dan emosi manusia. Dalam ilmu faal kuno dikenal unsur-unsur kimiawi manusia itu adalah : darah, lendir, cair empedu 
kuning dan cair empedu hitam, hubungan antara temperamen dan cair empedu kuning melahirkan atau menyebabkan temperamen pendengar merasa tergelitik(cair) sehingga memunculkan perasaannya menjadi lucu lalu terdorong untuk tertawa.Karenanya memungkiri bahwa aspek melucu melalui jalur humor dari kehidupan manusia adalah sesuatu yang mustahil, karena humor adalah bagian terdalam pada diri manusia.

Humor dalam terminologi bahasa Arab disebut dengan istilah al-Mazhu (المزح), disebutkan dalam Kamus al-Muhkam : "Makna al-Mazhu adalah lawan dari makna al-Jidd (الجد yang berarti Serius) Pensyarah kitab al-Qaamuus menyebutkan bahwa lafazh المز الحز (Al-Mizaahu) yaitu salah satu bentuk turunan dari lafazh المزح (Al-Mazhu) artinya "Membuat orang lain merasa senang dengan cara yang santun, penuh simpatik dan tidak menyakiti. Jadi, ia harus bersih dari unsur - unsur pelecehan dan penghinaan terhadap sesuatu. Adapun menurut istilah syari'at, al-Mazhu (canda) adalah bermakna menyenangkan perasaan orang lain dengan cara yang santun, penuh simpatik, dan tidak menyakiti.

Encyclopedia Brittanica pada permulaan ketika memberi ulasan tentang apa itu humor mengakui bahwa mustahil untuk mendefinisikan humor secara sempurna, bahkan Jaya Suprana menjelaskan bahwa sejak awal tahun 80-an sampai sekarang Perhimpunan Pecinta Humor di Semarang selalu mengundang tokoh-tokoh untuk mendefinisikan humor juga tidak terpecahkan bahkan setiap tahun didunia juga mengadakan acara Humour Word Congres yang membahas apa itu humor juga tidak menemukan kata sepakat.(Jaya Suprana Humorologi:2013) Jaya Suprana memasukan humor sebagai bagian dari Alasanologi; Pemicu kesan jenaka pada suatu bentuk humor adalah unsur kejutan diluar dugaan, logika, kelaziman, dan harapan; dan unsur kejutan pemicu kesan jenaka itu hadir pada alasan.(Jaya Suprana Humorologi,2013:88)

Berbagai macam definisi tentang Humor yang banyak dan beraneka variasi tentu tidaklah didapatkan satupun definisi yang disepakati, namun demikian humor dapatlah dilihat dari beberapa aspek sebagai berikut:

a) Sebagai stimulus, misalnya tayangan humor.

b) Sebagai respon, misalnya tersenyum.

c) Sebagai proses kognitif, misalnya pemahaman terhadap humor.

d) Sebagai karakter kepribadian, misalnya afek dan emosi positif yang dihasilkan oleh humor.

e) Sebagai intervensi terapeutik, misalnya terapi humor.

\section{Manfaat Humor}

Quraish Shihab (2014:4) seorang ahli tafsir Indonesia juga menaruh perhatian khusus terhadap humor, Beliau menulis buku berjudul " Yang Jenaka dari M.Quraish Shibab" dan pada bagian awal buku tersebut Beliau menulis dengan judul "Mengapa Tertawa" bahwa bisa jadi sebab utama tawa adalah "terjadinya sesuatu yang tidak terduga sebelumnya"

Kunjana Rahardi (2011:33) seorang ahli Bahasa Indonesia mengemukakan bahwa 
keanehan, kekonyolan, kelucuan, tuturan yang tidak bonafide, tuturan yang tidak seperti yang seharusnya, tuturan yang tidak disangka-sangka, yang semuanya itu bisa menciptakan keterbengongan, dan keterbengongan itu pada akhirnya akan memunculkan kejenakaan atau kelucuan, dan itupula yang mengakibatkan orang tersenyum dan tertawa. Dan perhatian Kunjana Rahardi dalam bidang Humor ini membuat Beliau menulis dua buah buku yaitu : Bahasa Jenaka" dan " Humor ada Teorinya Bahasa dan gaya melawak"

Jaya Suprana (2013:88) melahirkan tiga buah buku tentang humor yakni : “ Humoria ", "Alasanologi" dan "Humorologi", beliau mengemukakan bahwa Pemicu kesan jenaka pada suatu bentuk humor adalah unsur kejutan diluar dugaan, logika, kelaziman,harapan; dan unsur kejutan pemicu jenaka itu hadir pada alasan, Maka apabila kita membedah suatu bentuk humor memang kerap kali kita akan menemukan komponen alasan sebagai pemicu kesan jenaka. Tri Adi Sarwoko (2011:2) menulis : "Kelucuan terjadi jika ada suatu ketidaklaziman atau aneh"

Deddy Mulyana seorang profesor bidang Komunikasi juga menulis dua buah buku tentang humor yakni ;" Komunikasi Humoris Belajar Komunikasi lewat Ceritera dan Humor" dan "Komunikasi Jenaka", dimana kedua buah buku tersebut memaparkan bahwa kita ketawa salahsatu penyebabnya adalah karena ada perbedaan pemahaman akan simbol-simbol dalam komunikasi dikarenakan perbedaan budaya ( Komunikasi antar budaya). Ahli Komunikasi Indonesia lainnya yakni Jalaluddin Rakhmat (1996:126) memasukan humor sebagai bentuk pidato Rekreatif, dimana menurutnya orang tertawa karena adanya kesenangan.

Lalu apa manfaat Humor yang melahirkan reaksi senyum dan ketawa?, Humor adalah bagian kejenakaan yang ada dalam diri manusia yang berefek pada regulasi kesenangan dan kegembiraan yang tumbuh sebagai reaksi dari stimulus-stimulus yang ditimbulkan akibat adanya interaksi dalam diri manusia merespon terhadap stimulus yang dilihat, didengar dan dirabanya, akibat dari humor berupa senang, bahagia, gembira sebagai gejala alamiah dalam diri manusia yang merupakan lawan dari gejala kesengsaraan dan kesedihan manusia. Humor adalah alat atau media yang mencoba membuat sisi kegembiraan dalam diri manusia sehingga memunculkan efek-efek positif dalam diri manusia. Dan reaksi yang tampil mengemukakan dari respon terhadap humor adalah: Tersenyum dan Ketawa.

Beberapa ahli telah melakukan berbagai penelitian tentang senyum. Prof. James V. McConnell, seorang Psikolog di Universitas Michigan, Amerika Serikat, berkata, "Orang yang tersenyum cenderung mampu mengatasi masalah, mengajar orang lain, dan menjual barang dengan lebih efektif, serta membesarkan anak-anak dengan lebih bahagia. Ada lebih banyak informasi tentang senyuman daripada sebuah kerutan di kening. Sebab, senyum itulah yang mendorong semangat dan menjadi alat pengajaran yang jauh lebih efektif daripada hukuman (emosi)".

Ted W. Engstrom mengatakan bahwa senyuman dapat menciptakan kegembiraan, membuat suasana menjadi ceria, membantu mengembangkan 
keinginan yang baik dalam bisnis, membangkitkan semangat, dan mempererat hubungan dengan orang lain. Dari sisi psikologi, senyum dapat mengurangi stress dan mengubah perasaan. Ketika kita merasa tertekan dan sedih, cobalah tersenyum, maka perasaan akan lebih baik serta pikiran lebih jernih dan positif. Pada saat tersenyum, tubuh kita memberi sinyal-sinyal positif kehidupan. Dan, tersenyum mampu meningkatkan imunitas tubuh secara psikologis, karena senyum membuat perasaan dan pikiran lebih rileks.

Senyum ternyata juga bermanfaat bagi kesehatan dan kecantikan. Aktifitas senyum sama dengan olah raga yang bermanfaat untuk mengurangi infeksi paru-paru, mengurangi sakit jantung, meningkatkan semangat, mengurangi dua hormon dalam tubuh yaitu eniferin dan kortisol, serta menghasilkan endorphin, pemati rasa alamiah dan serotonin yang merupakan hormon pengendali rasa sakit, sehingga senyum bisa mempercepat proses penyembuhan penyakit dan mengurangi rasa nyeri.

Dari segi kecantikan, senyum merupakan obat awet muda karena senyum menggerakkan banyak otot wajah, sehingga otot wajah terlatih dan kencang. Senyum terbukti dapat merangsang otot-otot wajah dan memberi kesegaran dan mengurangi kerut-kerut di wajah, kesehatan tubuh dan jiwa dengan melepaskan tenaga emosi yang berpusat dari dalam.(Sofyan Hadi: 2008)

Berawal dari kegemarannya mengutarakan lelucon, ilmuwan saraf dari University College London, Profesor Sophie Scott, meneliti salah satu ekspresi manusia, yaitu tertawa. Dia lalu menjabarkan temuannya dan beberapa koleganya. Inilah lima fakta unik mengenai tertawa.:

1) Teman memicu tawa

Jika Anda ditanya, apa yang membuat Anda tertawa? Amat mungkin Anda menjawab lelucon dan humor. Namun, benarkah demikian? Robert Provine, seorang psikolog dari Universitas Maryland, Amerika Serikat, menemukan bahwa kita sejatinya paling banyak tertawa ketika berbicara dengan teman dan sahabat. Bahkan, kemungkinan kita akan tertawa saat kita bersama orang lain, meningkat 30 kali lipat. Yang menarik, tawa kita tidak dipicu oleh humor atau lelucon teman. Kita tertawa pada pernyataan dan komentar lawan bicara yang mungkin tidak selalu lucu. Tawa kita adalah bentuk komunikasi, bukan reaksi. Hal itu menunjukkan bahwa tawa ialah perilaku sosial yang kita lakukan guna menunjukkan kepada orang lain bahwa kita menyukai mereka dan kita memahami mereka.

2) Tawa Spontan dan Tawa buatan

Otak manusia secara otomatis dapat mengenali perbedaan ketika seseorang tertawa secara spontan atau dibuat-buat. Hal itu disebabkan otak manusia di bagian depan berfungsi untuk memahami emosi orang lain. Imbasnya, kita dapat langsung tahu apakah seseorang tertawa spontan atau disengaja, meskipun tiada pihak yang menyuruh kita untuk mendeteksi perbedaannya. 
3) Tawa itu menular

Riset pada otak menunjukkan bahwa ketika orang lain tertawa, meskipun dipicu oleh sesuatu yang tidak begitu lucu, otak kita merespons tawa tersebut dengan menginstruksikan otot-otot wajah untuk ikut tertawa. Lalu, begitu orang-orang lain ikut tertawa, otak kita semakin bisa menentukan apakah tawa itu spontan atau disengaja. Hal ini menjelaskan mengapa kita turut tertawa ketika banyak orang di sekitar kita tertawa lepas.

4) Tawa tidak membuat bugar

Apabila Anda melakukan pencarian di dunia maya tentang tertawa, ada banyak artikel yang mengklaim bahwa tawa baik untuk kesehatan. Itu memang benar, tapi jangan berpikir bahwa Anda bisa membakar kalori lebih banyak dengan tertawa ketimbang berlari. Walau tertawa mengeluarkan banyak energi, meningkatkan detak jantung sekitar 10\% hingga 20\%, dan membakar 10-40 kalori, hal itu bisa tercapai dengan tertawa selama 10 sampai 15 menit. Dengan demikian, Anda harus tertawa selama tiga jam nonstop untuk membakar kalori yang dihasilkan sekantong kentang goreng asin.

5) Hubungan awet muda

Psikolog dari Universitas Berkeley, Amerika Serikat, Profesor Bob Levenson melakukan penelitian dengan meminta sejumlah pasangan untuk mendiskusikan sesuatu tentang partner mereka yang dianggap mengganggu. Pasangan yang menggunakan tawa dan senyum saat berdiskusi tidak hanya merasa lebih baik, tapi juga merasakan tingkat kepuasan lebih tinggi dalam hubungan dan menjalin hubungan lebih awet. Hal ini menunjukkan bahwa tawa adalah emosi yang bisa kita gunakan dengan orang-orang dekat untuk membuat kita merasa lebih baik. (https://www.bbc.com/indonesia/majalah/2014/10/141026_iptek_tawa_lima,

diakses tanggal 08-03-2019)

Humor atau lelucon identik dengan kejenakaan atau kelucuan yang mengakibatkan orang tersenyum atau tertawa, yang menjadi pertanyaan adalah Apa yang menyebabkan orang tertawa?

Isa Alamsyah dalam bukunya " Humortivitas Mengubah dunia melalui Lawak" menulis sebagai berikut : Humor sudah sejak lama menjadi bagian kehidupan manusia, Bercanda(kidding), sendau gurau (joke), ngelawak (joking), melucu/lelucon (comedy), ngocol (make fun), banyol, ngerjain (practical joke/prank), parodi, adalah sedikit contoh bagaimana humor mengakar dalam masyarakat.Tidak hanya untuk hiburan dan tertawa, humor kini sudah meluas fungsinya dalam masyarakat.

Didunia politik, humor menjadi alat kritik yang efektif, sarana ekpresi protes masyarakat yang tidak bisa ditumpahkan melalui lembaga resmi, dan bahkan pemecah kebekuan diplomasi, Didunia pendidikan dan public speaking, humor adalah alat efektif untuk memecah kebosanan, ilmu yang disampaikan dengan bumbu humor akan lebih menarik untuk didengarkan, humor juga bisa menjadi 
cara lain memberi nasehat tanpa terkesan menggurui.

Dalam pergaulan, humor bisa menjadi daya tarik pertemanan, orang yang mempunyai paling banyak stok humor dan mampu memancing tawa, mendapat tempat khusus dalam pergaulan, didunia kesehatan humor bisa menjadi bagian dari terapi, selain menyehatkan, tertawa juga mengurangi tekanan jiwa. (Isa Alamsyah: 2004)

James Danandjaya (2002) ahli Foklor Indonesia menyatakan : manfaat humor pada umumnya, baik yang bersifat seks maupun protes sosial, yang terutama adalah sebagai pelipur hati pendengarnya (maupun penceritanya) yang sedang lara.Hal ini disebabkan karena humor dapat menyalurkan ketegangan batin, yang ada mengenai ketimpangan norma-norma masyarakat.

A Kang Mastur menulis buku " Humor Guru Sufi kiat dan Motivasi Menjadi Pendidik yang Humoris dan Inspiratif" bahwa humor bagi Guru bermanfaat untuk menghidupkan situasi belajar-mengajar, sekaligus pula menciptakan suasana yang tidak monoton dalam menyampaikan materi pembelajaran,Darmansyah juga mengemukakan perlunya Humor dalam proses pembelajaran yang disajikannya dalam bukunya yang berjudul : "Strategi Pembelajaran Menyenangkan dengan Humor",dan Jalaluddin Rakhmat dalam bukunya "Retorika Modern" berpendapat bahwa humor akan melahirkan pidato yang Rekreatif, yaitu pidato yang menghibur atau menyegarkan.

\section{Pembahasan}

Filosofi Humor Bagi Dakwah

Humor menurut istilah syari'at, al-Mazhu (canda) adalah bermakna menyenangkan perasaan orang lain dengan cara yang santun, penuh simpatik, dan tidak menyakiti.(Kementrian Wakaf dan Urusan Agama Kuwait, 1983:13571) Dalam kalangan umat Islam mayoritas berpandangan bahwasanya tidaklah boleh humor yang memunculkan tertawa secara berlebih-lebihan, alasan pendapat ini adalah sebagai berikut :

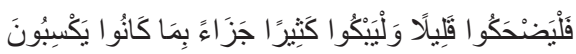

"Maka hendaklah mereka tertawa sedikit dan menangis banyak, sebagai pembalasan dari apa yang selalu mereka kerjakan" ( At Taubah:82)

Rasulullah Shallallahu 'alaihi wa sallam,

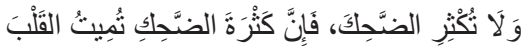

"Dan janganlah terlalu banyak tertawa. Sesungguh $\neg$ nya terlalu banyak tertawa dapat mematikan hati."

Larangan tertawa yang terdapat dalam hadits tersebut bersifat Qauliyah yakni perkataan langsung dari Rasulullah saw, sehingga dalam termilogi ilmu hadits bahwa hadits Qauli memiliki keshahihan yang lebih kuat/lebih diutamakan dari hadits yang bersifat fi'li (perbuatan), hal ini diperkuat dari ucapan Nabi 
Muhammad saw sebagai berikut:

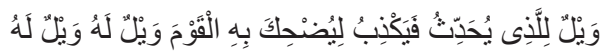

"Celakalah orang yang berbicara kemudian dia berdusta agar suatu kaum tertawa karenanya. Kecelakaan untuknya, Kecelakaan untuknya."

Rasulullah saw menasehati sikap sahabat yang tertawa ketika mendengar ada yang kentut.

$$
\begin{aligned}
& \text { "Mengapa kalian menertawakan kentut yang kalian juga biasa } \\
& \text { mengalaminya" }
\end{aligned}
$$

sedangkan hadits-hadits yang mengidentifikasikan bahwa Rasulullah saw tertawa adalah dalam tataran ranah fi'liyah atau perilaku Nabi yang dihabarkan oleh orang yang melihat atau mengetahuinya. Sebagaimana hadits dari Aisyah bahwa dia berkata:

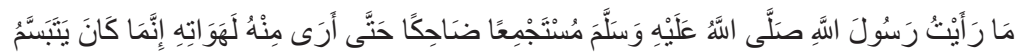

"Saya tidak pernah melihat Rasulullah shallallahu 'alaihi wasallam tertawa terbahak-bahak hingga kelihatan tenggorokan beliau, beliau biasanya hanya tersenyum.

Azharuddin Sahil merangkum kata tawa dalam tiga tempat. Masing-masing kata dikelompokkan berdasarkan imbuhan kata. Golongan pertama yakni "tawa" yang mendapatkan imbuhan "ter-" sehingga menjadi "tertawa". Ayat yang termasuk golongan ini adalah Qs. At-TAubah (9): 8, an-Naml (27): 19,. An-Najm (53): 43, dan 'Abasa (80): 39. Golongan ini menggambarkan tentang kebolehan tertawa dalam skala kecil dan fitrah tertawa bagi manusia.

Golongan selanjutnya yakni "tawa" mendapat imbuhan "mener _kan yang termaktup dalam beberapa tempat. Ayat-ayat yang membahas yakni Qs. AlMu"minun (23): 10, an-Najm (53): 60, al-Muthaffifin (83): 29, dan 34. "Menertawakan" dekat dengan pekerjaaan merendahkan. Namun, pada golongan ini pada Qs. 83 ayat 34 memberikan ungkapan tentang kebahagiaan penghuni surga yang menertawakan orang kafir yang disiksa. "tawa" dengan Imbuhan "Mener - kannnya" menjadi golongan terakhir dari pengklasifikisiannya. Imbuhan ini dapat ditemukan dalam Qs. Az-Zukruf (43): 47. Tertawa pada ayat tersebut berada dalam konteks menghina "Maka tatkala dia datang kepada mereka dengan membawa mukjizat-mukjizat Kami, dengan serta merta mereka menertawakannya

Perihal gurau, lawak, kelakar ulama memang berbeda pendapat. Sebagian ulama menghindari gurauan dan kelakar karena gurauan menurut mereka dapat mengurangi wibawa seseorang. Sementara sebagian ulama lainnya memandang bahwa kelakar justru melengkapi wibawa seseorang. 


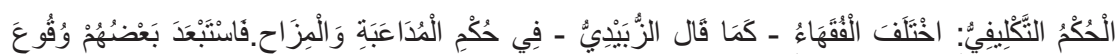

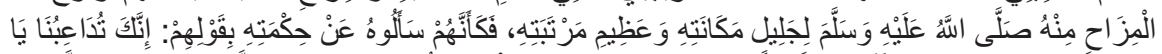

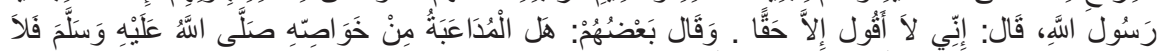

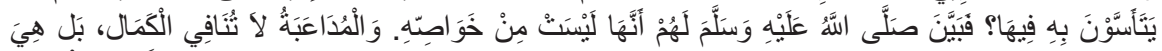

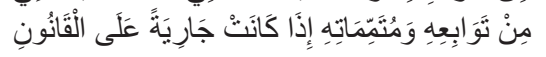

Artinya, "Sebagaimana pernyataan Az-Zubaidi, para ulama berbeda pendapat perihal gurau dan kelakar. Sejumlah ulama menganggap Rasulullah SAW jauh dari gurauan dan kelakar melihat kedudukan dan martabatnya yang mulia. Ketika para sahabat RA menanyakan, 'Apakah Engkau bergurau dengan kami ya Rasul?', Beliau menjawab, 'Aku tidak berkata selain kebenaran.' Dengan kata lain, sebagian sahabat bertanya, apakah gurauan itu khusus untuk Rasulullah SAW yang mana mereka tidak boleh mengikutinya? Rasul menerangkan, kebolehan bergurau itu bukan sebuah kekhususan baginya. Gurauan tidak menafikan kesempurnaan. Bahkan gurauan itu konsekuensi dan pelengkap kesempurnaan bila gurauan berjalan sesuai undang-undang."

Imam An-Nawawi secara jelas menyebutkan bahwa lawak, humor, dan kelakar itu bergantung pada porsinya. Sejauh tidak terperosok pada hal yang dilarang seperti merendahkan bahkan menyakiti orang lain, kelakar dan gurauan tidak masalah. Ketika dan kelakar mengarah pada pengecilan terhadap martabat orang lain, dilakukan secara berlebihan, atau melalaikannya dari kewajiban, humor dan lawak dilarang agama.

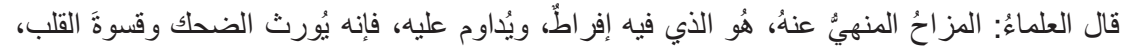

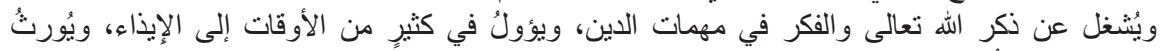

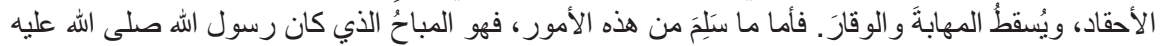

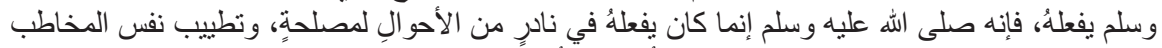

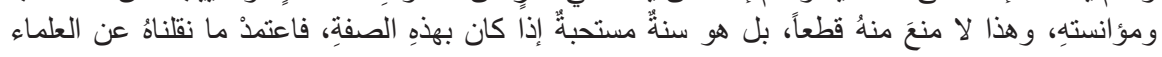

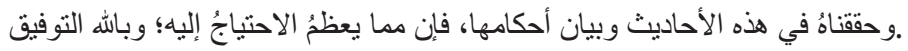

Artinya, "Para ulama berkata, 'Kelakar terlarang adalah kelakar yang berlebihan dan dilakukan terus-menerus karena menyebabkan senda gurau dan keras hati' serta dapat melalaikan zikir dan menyita perhatian yang semestinya diarahkan untuk memikirkan perihal penting dalam agama. Kecuali itu, kelakar sering kali menyakiti perasaan orang lain, memicu kebencian, dan menurunkan wibawa orang lain. Sementara kelakar yang jauh dari sifat-sifat itu dibolehkan seperti kelakar yang dilakukan Rasulullah SAW. Beliau melakukannya sesekali untuk kemaslahatan dan menghibur hati lawan bicara. Untuk ini tidak ada larangan sama sekali. Bahkan kelakar seperti ini sunah yang dianjurkan bila dilakukan sesuai sifat-sifat gurauan Rasulullah SAW. Pegang lah pendapat ulama yang kami rujuk, dan hadits berikut hukumnya yang kami teliti karena hampir semuanya dibutuhkan. Semoga Allah memberi taufiqnya,"

Agus Suhadi menulis sebuah buku yang berjudul : Humor itu Serius", dan pada umat 11 Maret 2016 diadakan seminar bertajuk "Humor Itu Memang Serius'. di Galeri Indonesia Kaya Grand Indonesia West Mall, lantai 8 dengan pembicara Jaya Suprana, Arswendo Atmowiloto, dan Seno Gumira Ajidarma (moderator). Jaya 
Suparana menulis buku dengan judul menggelitik "Alasanologi" dan "Humorologi", memasukan humor untuk sebuah ilmu, hal ini membuktikan bahwa keberadaan humor adalah sesuatu yang serius, bukan main-main, majalah Prisma Jurnal Pemikiran Sosial Ekonomi pada tahun 2019 menurunkan tulisan yang membahas tentang Humor dengan judul cover depan majalah tersebut berjudul : "Humor yang Adil dan Beradab".

Pinurbo dalam acara bincang sastra di Taman Budaya Yogyakarta (TBY), Sabtu (29/1), malam. Menyatakan : Jika ada anggapan bahwa humor hanya sebatas membuat orang tertawa saja, maka sepertinya perlu ada banyak diskusi tentang humor. Karena ternyata humor tak sekadar berhubungan dengan saraf tertawa saja, melainkan juga membutuhkan permainan logika, penguasaan bahasa, serta pengendalian emosi. Humor menjadi sesuatu yang dalam dan penuh makna.Humor ditempatkan dalam posisi yang "sangat serius" saat melihat dan mencerna apa yang terjadi dalam kehidupan sehari-hari. Dengan humor, seseorang akan bisa melihat banyak perspektif dan menjauhi cara pandang dengan kaca mata kuda.

Khaeron Sirin (2016) dalam kata pengantar bukunya yang berjudul : "Ketawa Sehat Bareng Para Ahli Fikih"menyatakan bahwa selama ini, humor selalu dikaitkan dengan sesuatu yang berbau porno, seks, pelecehan, ketololan, kasar dan diskriminatif yang jauh dari mencerdaskan, Qutub Izziddin Jamil Al-Syarwi (2016) dalam pengantar bukunya "Fikih Humor " menyatakan sayangnya tayangan komedi saat ini tersaji dalam dosis yang melebih kadar seharusnya serta tidak mendidik,bukan mustahil hal tersebut akan membentuk karakter masyarakat yang memiliki kepribadian anti sosial bahkan dekadensi moral.

Muhammad Muhibbuddin (2018:10) dalam bukunya " Humor Sufi Para Wali dan Kiai" menekankan bahwa humor hendaklah menekankan pada sisi nasihat: " dibalik keseriusan ada kelucuan, dibalik ketegangan ada keceriaan.Itulah barangkali sisi relasional antara nasihat dan humor.Nasihat sering diasosiasikan dengan sesuatu yang serius bahkan sakral, sementara humor dipandang sebagai sesuatu berbau lucu,.......ada berbagai cara untuk menyampaikan sebuah nasihat atau pesan salahsatunya adalah melalui humor.Seni menyampaikan nasihat melalui humor mempunyai kelebihan tersendiri, salahsatu sisinya menyegarkan, bisa menghilangkan kejenuhan dan kepenatan, kemudian disisi lain, humor (joke) bisa membuat seseorang yang dinasihati tidak tersinggung"

Ki Moesa A.Machfoeld (2004:108) memasukan humor berdakwah dengan metode lisan-Humor, dimana menurutnya Metode ini didasarkan atas fakta psikologis bahwa manusia diberikan rasa ingin senang, diantaranya senang melihat dan mendengar sesuatu yang lucu yang dapat menghilangkan rasa sedih. Namun Beliau memberikan peringatan : Yang penting dicatat dari metode ini adalah jangan sampai kelucuannya menghilangkan makna pesan dakwah kepada objek.Jika ini terjadi maka kegiatan dakwah akan jatuh kedalam "pseudodakwah", dakwah semu yang tidak mempunyai makna apa-apa karena tidak mampu menyampaikan pesan dakwah, sehingga sangat kecil kemungkinannya 
untuk melakukan perubahan dan mencapai tujuan dakwah, mengembalikan manusia kejalan Allah, kegiatan pseudodakwah hanya terfokus kepada tingkat kelucuan da'i, sehingga yang dominan kegiatan melucu, tepuk tangan dan tertawa.

Menurut Ustad Ibnu Mas'ud dalam artikel Generasi Salafus Sholeh (2014) "Hukum bercanda dalam islam", untuk menghindari terjadinya pseudo dakwah tersebut maka haruslah diperhatikan esensi darti eksistensi humor atau bercanda dalam berdakwah dengan memperhatikan "ilat (sebab) hukum humor atau bercanda yang terbagi dalam 4 (empat) sebab hukum :

1. Canda yang Mustahab (Dianjurkan atauDisunnahkan) Canda yang dianjurkan yaitu apabila suatu canda terkandung maslahat (manfa'at) dalam canda tersebut, seperti untuk menyenangkan orang yang diajak bicara dan mengakrabkan hubungan silaturrahim dengannya.

2. Canda yang Mubah (Boleh) Canda yang dibolehkan yaitu apabila suatu canda tidak mengandung manfaat (maslahat), tetapi pada waktu yang sama, canda itu bersih dari unsur-unsur yang diharamkan atau dimakruhkan, maka canda hukumnya mubah hukumnya.

3. Canda yang Makruh (Dibenci), Canda yang dibenci, yaitu canda dalam perkara yang hukumnya mubah (boleh) tetapi dilakukan dengan sering sekali dan berulang-ulang kali.

4. Canda yang Haram (Dilarang) Canda yang dilarang, yaitu canda yang mengandung unsur pelecehan terhadap agama.

Listya Istiningtyas (2014:12) dalam tulisannya berjudul: "Humor dalam Kajian Psikologi Islam", menyatakan bahwa ada beberapa hal yang tidak diperbolehkan dalam humor adalah :

1. Tidak menjadikan simbol-simbol Islam (tauhid, risalah, wahyu dan dien) sebagai bahan gurauan.Firman Allah: "Dan jika kamu tanyakan mereka (tentang apa yang mereka lakukan itu), tentulah mereka akan menjawab, "Sesungguhnya kami hanyalah bersenda gurau dan bermain-main saja."Katakanlah: 'Apakah dengan Allah, ayat-ayat-Nya dan rasul-Nya kamu selalu berolok-olok?" (QS. at-Taubah:65)

2. Tidak berbohong dan mengada-ada sebagai alat untuk menjadikan orang lain tertawa. Sabda Rasulullah saw: "Celakalah bagi orang yang berkata dengan berdusta untuk menjadikan orang lain tertawa. Celaka dia, celaka dia." (HR. Ahmad, Abu Dawud, Tirmidzi dan Hakim).

3. Tidak mengandung penghinaan, meremehkan dan merendahkan orang lain, kecuali yang bersangkutan mengizinkannya.Firman Allah: "Wahai orang-orang yang beriman! Janganlah suatu kaum mengolok-olok kaum yang lain, (karena) boleh jadi mereka (yang diperolok-olokkan lebih baik dari mereka (yang mengolok-olok), dan jangan pula perempuanperempuan (mengolok-olokkan) perempuan lain, (karena 
boleh jadi perempuan (yang diperolok-olokkan lebih baik dari perempuan (yang mengolok-olok). Janganlah kamu saling mencela satu sama lain, dan janganlah saling memanggil dengan gelar-gelar yang buruk. Seburuk buruk panggilan adalah (panggilan) yang buruk (fasik) setelah beriman. Dan barangsiapa yang tidak bertobat, maka mereka itulah orang-orang yang dzalim" (QS. al-Hujurat:11).

4. Tidak menimbulkan kesedihan dan ketakutan terhadap orang muslim.Sabda Nabi SAW: "Tidak halal bagi seseorang menakut-nakuti sesama muslim lainnya." (HR. ath-thabrani.) "Janganlah salah seorang di antara kamu mengambil barang saudaranya, baik dengan maksud bermain-main maupun bersungguh-sungguh." (HR. Tirmidzi)

5. Tidak bergurau dalam urusan yang serius dan tertawa dalam urusan yang sedih.Tiap-tiap sesuatu ada tempatnya, tiap-tiap kondisi ada (cara dan macam) perkataannya sendiri. Allah mencela orang-orang musyrik yang tertawa ketika mendengarkan Al-Qur'an padahal seharusnya mereka menangis, lalu firman-Nya :"Maka apakah kamu merasa heran terhadap pemberitaan ini? Dan kamu menertawakan dan tidak menangis. Sedang kamu melengahkannya." (QS. an-Najm:59- 61).

6. Tidak berlebihan dan keterlaluan. Dalam hal hiburan Rasulullah memberikan batasan dalam sabdanya; Janganlah kamu banyak tertawa, karena banyak tertawa itu dapat mematikan hati." (H R. Tirmidzi). "Berilah humor dalam perkataan dengan ukuran seperti Anda memberi garam dalam makanan."(Ali ra.).

\section{Simpulan}

Secara filosofis Fungsi Humor dalam dakwah berbentuk ceramah adalah agar ceramah yang disampaikan Pendakwah bersifat rekreatif untuk menghindarkan kebosanan obyek dakwah didalam mendengar atau menyerap isi dari ceramah tersebut, karenanya seorang Penceramah haruslah dapat membedakan Humor atau Candaan dengan Lawakan/Dagelan, Humor atau Candaan menampilkan sesuatu yang serius dan berbeda dengan Lawakan/Dagelan, Lawakan/Dagelan cenderung memporsikan kelucuan daripada Humor walaupun sebenarnya keduanya untuk memancing tawa orang yang mendengarkannya, setiap orang bisa melawak akantetapi humor tidak bisa dilakukan oleh setiap orang.Sebagai contoh KH.Abdurahman Wahid adalah seorang Humoris bukan Pelawak, tetapi Marwoto (Ketoprak Pelesetan) adalah seorang Pelawak tetapi bukan Humoris.

Terkadang, humor dalam berdakwah memang dibutuhkan dan Rasulullah seringkali juga menyampaikan dakwah melalui humor kepada para sahabat agar mudah diterima, filosofi Humor dalam Dakwah hanyalah sebagai pelengkap untuk menghidupkan suasana situasional kegiatan dakwah yang sedang dilaksanakan agar terhindar dari keterbosanan obyek dakwah.

Oleh karena itu, penggunaan Humor dalam berdakwah harus 
dipersiapkan secara selektif agar sesuai dengan konteks tema ceramah atau dakwah serta haruslah memperhatikan keseimbangan forsi materi pesan dakwah dengan humor yang disajikan dalam berdakwah secara lisan agar terhindar dari pseudo dakwah yakni aktivitas dakwah semu yang melenceng dari tujuan dari dakwah Islamiyah.

\section{Referensi}

A.Machfoeld, Ki Moesa. 2004. Filsafat Dakwah, Ilmu Dakwah dan Penerapannya. Bulan Bintang: Jakarta

Alamsyah, Isa. 2014. Humortivitas Mengubah dunia melalui Lawak. Asma Nadia Publishing House: Depok

Alniezar, Fariz. 2019. Homo Homini Humor. Basabasi: Yogyakarta

Damayanti, Deni. 2017. Jurus Sakti Menjadi Guru Humoris berkarakter mulia dan berkepribadian positif. Araska: Jogjakarta

Danandjaya, James. 2002. Asli Humor Mahasiswa. Pustaka Sinar Harapan: Jakarta

Elison, Eddi. 2014. Ketawa Bareng Bung Besar. Imania: Depok

Greg Dean. 2012. Step By Step Stand Up Comedy, Terj. Ernest Prakasa. Kawah Media: Jakarta

Haqiqi AK. 2008. Senyum dan Gurauan Rasulullah SAW. Lintas Media: Jombang

Islam Ahmad bin Ali, Abu. 2008. Dhahkah wa Ibtisamah li an Nabi saw, terj. Abdul Aziz Noor. Nakhlah Pustaka: Jakarta

Kementrian Wakaf dan Urusan Agama Kuwait. 1983. Al-Mausu'ah Al-Fiqhiyah Al-Kuwaitiyah. Kementrian Wakaf dan Urusan Agama Kuwait

Khaeron Sirin. 2016. Ketawa Sehat Bareng Para Ahli Fikih. Pustaka liman: Bandung

Listya Istiningtyas. "Humor dalam Kajian Psikologi Islam http://jurnal.radenfatah.ac.id/index.php/JIA/article/view/479/429

Mulyana, Deddy. 2006. Komunikasi Jenaka Parade Anekdot, Humor \& Pengalaman Konyol. PT.Remaja Rosdakarya: Bandung

Muhammad Abdullah Walid Karim. 2018. Al-Mizan Fi as-Sunnah, terjemah Izzuddin Karimi. Darul Haq: Jakarta

Muhammad Quraish Shihab. 2014. Yang Jenaka dari M.Quraish Shihab. Lentera Hati: Jakarta Muhibbuddin, Muhammad. 2018. Humor Sufi Para Wali dan Kiai. Araska: Yogyakarta

Muhyiddin Abu Zakaria An-Nawawi. Al-Adzkar. Darul Hadits: Kairo

Pakana, Ramon. 2016. Stand Up Comedy Indonesia. Kompas Gramedia: Jakarta

Prisma Jurnal Pemikiran Sosial Ekonomi. 2019. Humor Yang Adil dan Beradab Volume 38

Qutub Izziddin Jamil Al-Syarwi,Lc. 2016. Fikih Humor. Perpustakaan Mutamakkin Press: Jawa Tengah

Rahardi, Kunjana. 2011. Humor ada teorinya, bahasa dan gaya melawak. Pinus Book Publisher: Yogyakarta

Rakhmat, Jalaluddin. 1996. Retorika Modern. PT Remaja Rosdakarya: Bandung

Sahil, Azharuddin. 2007. Indeks al-Qur"an: Panduan Mudah Mencari Ayat dan Kata Dalam alQur'an. PT. Mizan Pustaka: Bandung

Sayyid bin Ahmad Mahmudah. 2015. Al- Mizah Adabun wa Ahkamun, terj.Yunus, S.Ag, Pustaka Imam Syafii: Jakarta

Sarwoko, Tri Adi. 2011. Sukses Melawak cara jitu mempersiapkan kreatif komedi hingga performance. CV.Andi Offset: Yogyakarta

Sudarmo, Darminto M. 2004. Anatomi Lelucon di Indonesia. PT.Kompas: Jakarta

Suhardi, Agus. 1992. Humor itu Serius. Grafikatama Jaya: Jakarta

Suprana, Jaya. 2013. Alasanologi. Kompas Gramedia: Jakarta

Tejo, Sujiwo. 2018. Kelakar Madura buat Gus Dur. Imania: Pondok Cabe

Wibi AR. 2003. Guyon Orang-orang Makrifat. Al Mawardi Prima: Jakarta

------. 2008. Komunikasi Humoris Belajar Komunikasi Lewat Ceritera dan Humor, Simbiosa Rekatama Media: Bandung 
-----. 2013. Humorologi. Kompas Gramedia: Jakarta

-----. 2014. Kelirumologi Genderisme. PT Elex Media Komputindo: Jakarta

Internet:

https://www.facebook.com/notes/muda-mudi-muslim/dagelan-melawak-dalam dakwah/211030045663961/ diakses tanggal 07-03-2019)

http://syofyanhadi.blogspot.com/2008/07/senyum-dan-tawa-menurut-al-quran.html, diakses tanggal 08-03-2019.

https://id.wikipedia.org/wiki/Humor 